\title{
$\alpha$-cardiac actin is a novel disease gene in familial hypertrophic cardiomyopathy
}

\author{
Jens Mogensen, ${ }^{1,2}$ Ib C. Klausen, ${ }^{1}$ Anders K. Pedersen, ${ }^{1}$ Henrik Egeblad, ${ }^{1}$ Peter Bross, ${ }^{2}$ \\ Torben A. Kruse, ${ }^{3}$ Niels Gregersen, ${ }^{2}$ Peter S. Hansen, ${ }^{1}$ Ulrik Baandrup, ${ }^{4}$ and Anders D. Børglum ${ }^{5}$ \\ ${ }^{1}$ Department of Cardiology, and \\ ${ }^{2}$ Research Unit for Molecular Medicine, Skejby University Hospital, Brendstrupgaardsvej, DK-8200 Aarhus N, Denmark \\ ${ }^{3}$ Department of Clinical Biochemistry and Genetics, Odense University Hospital, DK-5000 Odense C, Denmark \\ ${ }^{4}$ Institute of Pathology, Aarhus University Hospital, AaKH, DK-8000 Aarhus C, Denmark \\ ${ }^{5}$ Institute of Human Genetics, University of Aarhus, DK-8000 Aarhus C, Denmark
}

Address correspondence to: Jens Mogensen, Department of Cardiology, Skejby University Hospital, Brendstrupgaardsvej, DK-8200 Aarhus N, Denmark. Phone: 45 89496234; Fax: 45 89496009; E-mail: skejjm@aau.dk.

Received for publication February 4, 1999, and accepted in revised form April 14, 1999.

We identified the $\alpha$-cardiac actin gene $(A C T C)$ as a novel disease gene in a pedigree suffering from familial hypertrophic cardiomyopathy (FHC). Linkage analyses excluded all the previously reported FHC loci as possible disease loci in the family studied, with lod scores varying between -2.5 and -6.0 . Further linkage analyses of plausible candidate genes highly expressed in the adult human heart identified ACTC as the most likely disease gene, showing a maximal lod score of 3.6. Mutation analysis of ACTC revealed an Ala295Ser mutation in exon 5 close to 2 missense mutations recently described to cause the inherited form of idiopathic dilated cardiomyopathy (IDC). ACTC is the first sarcomeric gene described in which mutations are responsible for 2 different cardiomyopathies. We hypothesize that $A C T C$ mutations affecting sarcomere contraction lead to FHC and that mutations affecting force transmission from the sarcomere to the surrounding syncytium lead to IDC.

J. Clin. Invest. 103:R39-R43 (1999).

\section{Introduction}

Familial hypertrophic cardiomyopathy (FHC) is inherited as an autosomal dominant disease with a prevalence of about 1 in 500 and is characterized by unexplained hypertrophy of the heart muscle. The hypertrophy predominantly involves the interventricular septum, although any localization within the myocardium may appear. Eventually, about $10 \%$ of the patients exhibit progressive wall thinning with dilation of the left ventricle. Typical morphological changes include myocyte hypertrophy with myocytic fiber disarray surrounding areas of increased connective tissue. Clinically, the condition ranges from an asymptomatic course to incidents of dizziness and syncopes, chest pain, and symptoms of heart failure. FHC is also a major cause of sudden cardiac death among young, otherwise healthy athletes (1). Our understanding of the pathophysiological basis of the disease has increased dramatically during the last decade, not in the least because of genetic investigations. Disease-causing mutations have been described in 7 different genes, all encod- ing sarcomeric polypeptides. Therefore, FHC is assumed to be a disease of the heart sarcomere. The current hypothesis suggests that FHC is caused by impaired contractile performance of the sarcomere, leading to a compensatory hypertrophy of the heart $(2,3)$. More than 100 mutations have been reported, and missense mutations are the most prevalent type of change within the following genes encoding the polypeptides given in parentheses: $M Y H 7$ ( $\beta$-myosin heavy chain), TNNI3 (troponin I), TNNT2 (troponin T), TPM1 $(\alpha-$ tropomyosin), MYBPC3 (myosin-binding protein C), MYL2 (regulatory myosin light chain), and MYL3 (essential myosin light chain) (4). Furthermore, a disease locus on chromosome 7 has been linked to FHC, but the gene remains to be identified (5). Despite the numerous disease loci, it has not been possible to reveal mutations in the known disease genes in a substantial part of FHC families. In recent studies of French and Asian populations, it was possible to identify mutations in only $57 \%$ of the FHC cases $(6,7)$. These results indicate that not all FHC genes have been identified yet.
The present study reports on the investigation of a large FHC family, leading to the identification of a novel disease gene.

\section{Methods}

Clinical evaluations. Eight families were studied. Clinical investigations and blood samples for DNA analyses were obtained from family members after informed written consent, in accordance with local institutional review committee guidelines. Echocardiography was performed and analyzed by senior cardiologists. Standard 12-lead electrocardiograms were obtained with individuals in supine position during quiet respiration. Both examinations were performed and evaluated essentially as described previously (8). In brief, an individual was considered to fulfill major diagnostic criteria if the maximal wall thickness (MWT) measured by echocardiography was $>13 \mathrm{~mm}$ or if the electrocardiogram presented either major Q-wave abnormalities, left ventricular hypertrophy, or marked repolarization alterations. Individuals were considered to fulfill minor diagnostic criteria if their electrocardiogram presented minor $\mathrm{Q}$ waves in at least 2 leads or minor ST-segment changes (individuals III-4 and III-8; Table 1). Minor echocardiography criteria were considered to be fulfilled by an MWT of $13 \mathrm{~mm}$, mitral valve prolapse, and mitral regurgitation (individual II-8; Table 1). Before DNA analyses, all individuals were classified as having major or minor FHC phenotypes.

Linkage analysis. Pairwise and multipoint linkage analyses were carried out using the LINKAGE 5.1 package (http://linkage.rockefeller.edu/index.html) (9). The same age-dependent penetrances were used in linkage analyses of all genes except $M Y B P C 3$, which is known to be late onset (penetrances given in parentheses): age $<30$ years, 0.60 (0.45); age between 30 and 49 years, $0.80(0.60)$; and age $>50$ years, 0.95 $(0.80)$ (10). The frequency of phenocopies was defined as the prevalence of the disease (1 in 500). Initial linkage analyses consid- 
a

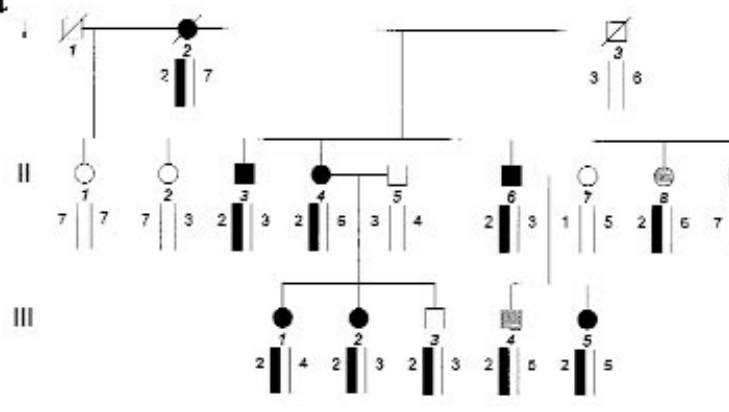

b

Mutant

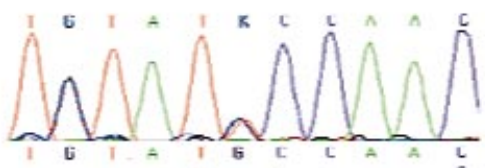

Wild-type

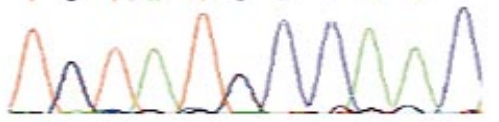

Figure 1

(a) Pedigree drawing of the FHC family carrying the ACTC Ala295Ser mutation. Individual numbers are given in italics, and symbols are defined as follows: squares, men; circles, women; diagonal slashes, deceased; open symbols, unaffected individuals; filled symbols, affected individuals fulfilling major diagnostic criteria; shaded symbols, affected individuals fulfilling minor diagnostic criteria; hatched symbols, excluded from linkage analyses because of hypertension. Alleles defined by the STR polymorphism within ACTC are shown in roman numerals (16). Thin bars indicate normal genotype of ACTC; thick bars indicate ACTC mutation segregating with allele 2 . The genotype of individual I-3 was inferred from offspring. Individuals II-3 and II-8 have 2 children each who did not want to participate in this investigation. This may well influence the otherwise surprising observation that all individuals of the third generation carry the mutant allele. (b) Sequence of the ACTC wild-type and the G253 $\rightarrow$ T mutated allele.

ered individuals fulfilling major diagnostic criteria as affected ( $n=10$ individuals), whereas individuals fulfilling minor diagnostic criteria were considered unknown and thereby excluded from these analyses $(n=3)$. In subsequent linkage analyses, individuals fulfilling minor diagnostic criteria were considered as affected and were included in the analyses. One individual was excluded from all analyses because of hypertension. Previously published polymorphic short tandem repeats (STRs) were used to perform linkage analyses of the following genes: ACTA1 (11), MYL3 (12), the FHC locus on chromosome 7 (5), MYBPC3 (13), MYH7 (14), TPM1 (15), АCTC (16), TNNI3 (17), and MYL2 (6). TNNT2 was localized in an interval of $6.7 \mathrm{cM}$ between the markers D1S1660 and D1S504, odds $300: 1$, by integrating mapping information from various databases and a genetic map $(12,18,19)$. Genomic DNA was isolated from either whole blood using a DNA isolation kit (Puregene D-5500; Gentra Systems, Minneapolis, Minnesota, USA) or from paraffin blocks containing lymph node tissue (individual I-2; Table 1) (20). Sense primers were labeled with the fluorescent dyes FAM, HEX, or TET. PCRs were carried out in a total volume of $6 \mu \mathrm{L}$ with $40 \mathrm{ng}$ DNA, $0.6-2.4 \mathrm{pmol}$ of each primer, $50 \mu \mathrm{M}$ dNTP, $1 \times$ standard PCR buffer (Perkin-Elmer Corp., Norwalk, Connecticut, USA), and 0.25 U AmpliTaq Gold DNA Polymerase (Perkin-Elmer Corp.). Amplifications were carried out using an initial denaturation step $\left(10\right.$ minutes at $\left.96^{\circ} \mathrm{C}\right)$, followed by annealing $\left(30\right.$ seconds at $55^{\circ} \mathrm{C}$ ), extension $\left(1\right.$ minute at $\left.72^{\circ} \mathrm{C}\right)$, and denaturation $\left(30\right.$ seconds at $96^{\circ} \mathrm{C}$ ) for $30-35$ cycles, and a final extension step $\left(8\right.$ minutes at $\left.72^{\circ} \mathrm{C}\right)$ using a GeneAmp PCR System 9700 (PerkinElmer Corp.). The PCR products were analyzed on an ABI prism 377 DNA sequencer according to the manufacturer's instructions (Perkin-Elmer Corp.).
Mutation analysis. Primers were designed according to the published genomic sequence of ACTC using the OLIGO 4.1 primer analysis software (MedProbe AS, Oslo, Norway) (21). Primer sequences were as follows: exon 1F: 5'-TGCAGAAACCCCCTGAAGC-3'; exon 1R: 5'-GCCATTTCCTAGATCGCTGGA-3'; exon 2F: 5'-TTCCTGACATGGTGAGAGCA-3'; exon 2R: $5^{\prime}$-TCGGTGACTTGGG AATGTG-3'; exon 3F: 5'-GAGCAGTGGTGTTGTCCTCAG-3'; exon 3R: 5'-AAGCAGACCCACACTGTGG-3'; exon 4F: 5' TTCTTGCTTCAGAGCATGACTG-3'; exon 4R: 5'-AAGATTTCCAGGAAAATCGTGC-3'; exon 5F: 5'-TTGACCTGAATGCACTGTGATG-3'; exon 5R: 5'-TAGAATACCAAGACCTGCCTCG-3' (to verify the G253 $\rightarrow$ T mutation in the forward direction of exon 5 , it was necessary to design the following sequencing primer downstream of the STR polymorphism [16]: 5'-GGCACTCATGA AACAACTTAC-3'); exon 6F: 5'-TTGGAACTTCAGAGTTCACTGG-3'; exon 6R: 5'-AAGAAGCATAATACCGTCATCC-3'. PCR product sizes for exons $1-6$ were $223,425,259$, 282,312 , and $242 \mathrm{bp}$, respectively. PCR was performed as already described in a final volume of $50 \mu \mathrm{L}$ using $10 \mathrm{pmol}$ of each primer and 1 U AmpliTaq Gold DNA Polymerase. The annealing temperature used to amplify exons 2 and 3 was $57^{\circ} \mathrm{C}$. The PCR products were purified using a PCR purification kit (catalog no. 28104; QIAGEN Inc., Valencia, California, USA) before cycle sequencing. Forward and reverse dRhodamin terminator cycle sequencing was performed using a DNA sequencing kit (cata$\log$ no. 403042; Perkin-Elmer Corp.) with a modified protocol using $20 \mathrm{ng}$ of the PCR product, 5 pmol of each primer, and $4 \mu \mathrm{L}$ of terminator-ready reaction mixture in a final volume of $15 \mu \mathrm{L}$. The sequences were analyzed on an ABI prism 377 DNA sequencer as already described.
Ssp1 restriction cleavage. Two Ssp1 restriction sites were introduced into the PCR product of exon 5. A forward primer containing the Ssp 1 site was designed next to the mutation (5'-TGATATCCGCAAGGACCAATAT-3'). An Ssp 1 site was also incorporated into the reverse primer $\left(5^{\prime}\right.$-CTTAGAATACCAATATTTGCCTCG-3') serving as a positive control. PCR amplification was performed as already described, with an annealing temperature of $55^{\circ} \mathrm{C}$. Ssp 1 cleavage was performed using $10 \mu \mathrm{L}$ PCR product, $1 \times$ NEB2-buffer, and 15 U Ssp 1 enzyme (New England Biolabs Inc., Beverly, Massachusetts, USA) in a final volume of $30 \mu \mathrm{L}$. The reaction mixture was incubated for 12 hours at $37^{\circ} \mathrm{C}$, and an additional $7.5 \mathrm{U}$ of Ssp 1 enzyme was added for 2 hours. The products were analyzed by $12 \%$ PAGE and made visible by ethidium bromide staining.

\section{Results}

Clinical investigations. The FHC family investigated (Figure 1a) displayed heterogeneous phenotypes, with the majority of affected individuals having no symptoms (Table 1 ). However, individual II-4 had pronounced septal hypertrophy of $30 \mathrm{~mm}$, with a left ventricle outflow tract (LVOT) gradient of $64 \mathrm{mmHg}$ at the age of 46 (Figure 2a). Echocardiography performed over the years showed a steady decrease in wall thickness (presently $13 \mathrm{~mm}$ ) and the development of mild aortic regurgitation (AR). The patient had frequent incidents of dizziness and syncopes caused by nonsustained ventricular tachycardia and had progressive symptoms of heart failure due to diastolic dysfunction of the left ventricle. Heart biopsy specimens taken at ages 46 and 


\section{Figure 2}

(a) M-mode echocardiogram of individual II-4 at age 46. The lower arrow indicates systolic anterior motion of the mitral valve typical of obstructive FHC. AO, aorta. IVS, interventricle septum varying in thickness between 20 and $30 \mathrm{~mm}$. LA, left atrium. LV, left ventricle. (b) Endomyocardial biopsy from individual II-4's right ventricle, stained with hematoxylin and eosin. The biopsy fulfilled histological FHC criteria by the presence of marked myocyte hypertrophy, increased amounts of loose connective tissue, and disarray of the myofibrils (32).

56 showed identical morphological features consistent with FHC (Figure 2b). The patient's mother, individual I-2, had progressive symptoms of heart failure beginning in her late sixties. The heart was dilated with an ejection fraction of $25 \%$, and individual I- 2 was classified as having end-stage FHC because she gave birth to 5 children fulfilling FHC diagnostic criteria. Individual III-1 had recurrent episodes of palpitations and syncopes at the age of 32 caused by an accessory atrioventricular conduction pathway known as the Wolff-Parkinson-White syndrome (WPW). Her initial echocardiogram showed borderline hypertrophy in the posterior part of the septum, which, over a 7-year period, enlarged significantly from $12 \mathrm{~mm}$ to $19 \mathrm{~mm}$. Individual II-6 had a septal bulge in LVOT and mild AR recorded by Doppler echocardiography. It is not likely that

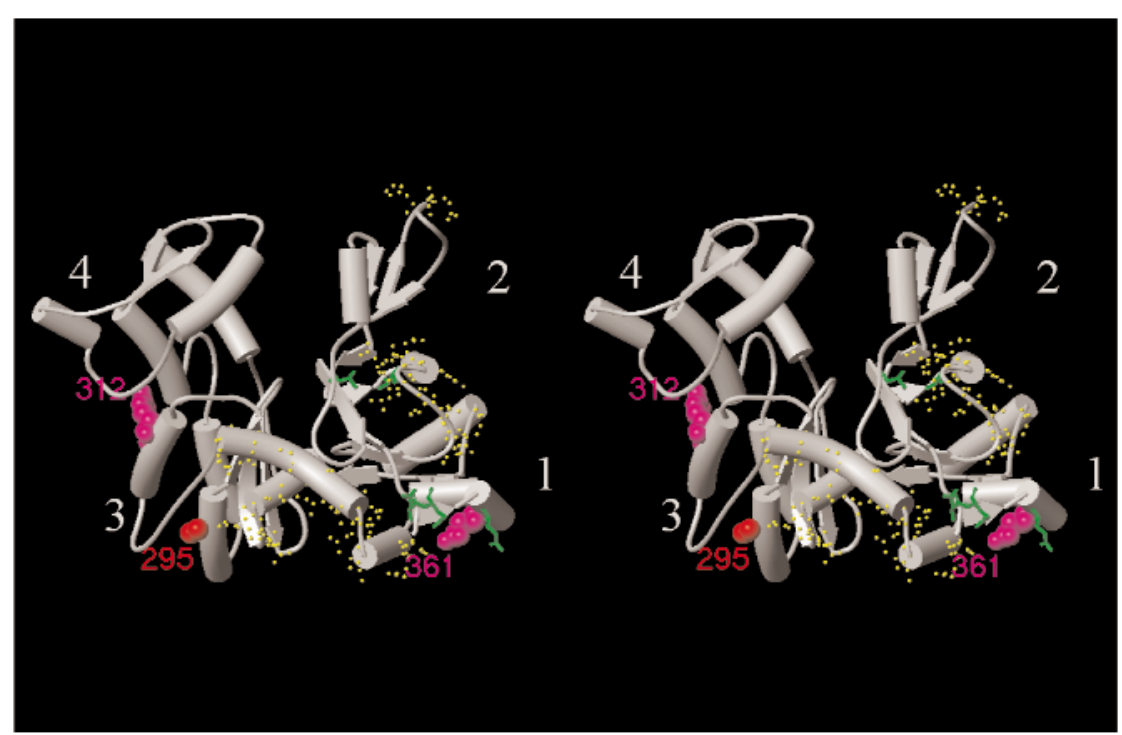

Figure 3

Schematic stereo representation of the actin monomer based on the crystal structure of actin (33) Putative binding sites to myosin are in yellow (28). The Ala295 amino acid mutated in the FHC family is shown in red and localized at the actin surface close to a possible myosin-binding site. The 2 amino acids mutated in IDC (Arg312 and Glu361) are shown in purple. The amino acid differences between $\alpha$-cardiac actin and the $\gamma$-enteric actin expressed in the transgenetically modified ACTC knockout mouse are demonstrated in green. The figure was prepared using the protein database (34). the observed AR caused the very localized hypertrophy, as only severe AR is known to cause global hypertrophy of the left ventricle (22). In addition, individual II- 6 is the father of a child (III-5) fulfilling major FHC criteria, making him an obligate carrier of the
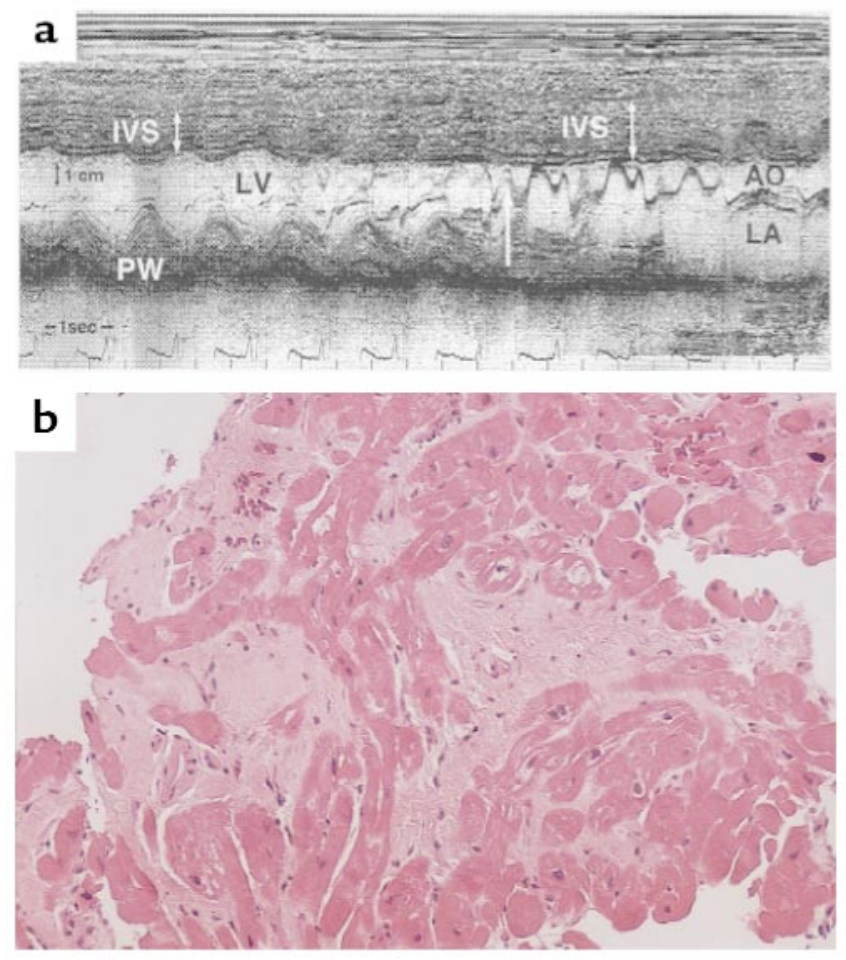

disease gene. The remaining affected family members were characterized by having an abnormal electrocardiogram, and most of them had a septal bulge in LVOT. Individual III-6 had an early onset of disease, presenting at the age of 4 with a heart murmur caused by a septal bulge in the LVOT.

Genetic investigations. Linkage analyses of all the known disease loci were performed using highly polymorphic STRs. Pairwise and multipoint linkage analyses excluded linkage to all these loci, with lod scores varying between -2.5 and -6.0 using age-specific penetrances and major diagnostic criteria. Additional linkage analyses tested the candidate genes ACTA1 (encoding $\alpha$ skeletal actin) and ACTC (encoding $\alpha$ cardiac actin), both of which are highly expressed in the adult human myocardium (23). A multipoint lod score of -5.5 excluded ACTA1, whereas $A C T C$ was most likely to be the disease gene, showing maximal lod scores of 2.7 and 3.6 at zero recombination fraction using major and minor diagnostic criteria, respectively. Sequence analysis of $A C T C$ identified a $\mathrm{G} \rightarrow \mathrm{T}$ mutation in position 253 of exon 5 resulting in an Ala295Ser amino acid substitution (Figure 1b). The mutation was localized on the haplotype cosegregating with the disease (Figure 1a). The presence of the mutation was confirmed by an $S s p 1$ 
restriction enzyme cleavage assay. All the mutated alleles were digested as expected, leaving the wild-type allele intact (data not shown). To exclude the possiblity that the mutation identified was a common polymorphism, 300 chromosomes from healthy individuals were investigated by either sequencing and Ssp 1 cleavage (150 chromosomes) or Ssp1 cleavage alone (150 chromosomes). No sequence variations were identified, confirming a previous investigation of 870 chromosomes by SSCP analysis of exon 5 (24). This is in accordance with the observation that $\alpha$-cardiac actin is highly conserved throughout evolution, including the Ala295 amino acid, which is conserved in 19 different species (25). In conclusion, strong evidence was found that the Ala295Ser substitution was the diseasecausing mutation and that ACTC is the eighth FHC gene. The expression of the actin mutation in this family gave the impression of a highly penetrant disease with diverse phenotypes and a vari- able age of onset. Only one individual (III-3, age 28) of 13 family members carrying the mutant allele was nonpenetrant, and morbidity was low, as only 3 of 13 family members carrying the mutant allele had symptoms of the disease.

\section{Discussion}

The highly conserved actins are the major constituents of the thin filaments in the muscle sarcomere. They are involved in force generation within the sarcomere and force transmission from the sarcomere to the surrounding syncytium. In accordance with its functional role, actin is known to interact directly with the thick-filament polypeptide ( $\beta$-myosin heavy chain), other thin-filament polypeptides (the light chains, troponin I, $\alpha$-tropomyosin), and anchor polypeptides (actinin, dystrophin) (26-29). The Ala295Ser substitution identified is localized at the surface of actin in proximity to a putative myosin-binding site (28) (Figure 3 ). The side chain of alanine 295 is sit- uated in a surface valley formed by polar and hydrophobic atoms lying between protruding charged actin residues including arginine 147 , which forms the outer edge of an actin/myosin-binding site. The introduction of the polar hydroxyl group of serine may distort the surface topology, leading to an impaired myosin binding. Thereby, an adequate contraction of the sarcomere would be prevented, resulting in a compensatory hypertrophy as seen in animal models $(30,31)$. Recently, 2 missense mutations in ACTC were reported to cause idiopathic dilated cardiomyopathy (IDC) in 2 unrelated families (24). The mutations were localized in the immobilized end of actin that cross-binds to the anchor polypeptides in the $\mathrm{Z}$ bands. The altered actin was suggested to impair force transmission by defective attachment to the anchor polypeptides. Therefore, it seems likely that mutations in ACTC lead to FHC when they involve force generation within the sarcomere, and to IDC when

Table 1

Clinical features of the FHC family carrying the ACTC Ala295Ser mutation

\begin{tabular}{|c|c|c|c|c|c|c|}
\hline Pedigree & Age/sex & Symptoms & Electrocardiogram & Echocardiogram & Phenotypic assignment & ACTC genotype \\
\hline $\mathrm{I}-2^{\mathrm{A}}$ & $* 76 \mathrm{~F}$ & Heart failure & Atrial flutter, LBBB & End-stage FHC & FHC-major & Ala295Ser ${ }^{B}$ \\
\hline $\mathrm{I}-3^{\mathrm{A}}$ & $* 84 \mathrm{M}$ & Angina, dyspnea & $\begin{array}{l}\text { Previous myocardia } \\
\text { infarctions }\end{array}$ & No data & IHD & No data \\
\hline II-1 & $62 \mathrm{~F}$ & No & Normal & Normal & Normal & Normal \\
\hline II-2 & $59 \mathrm{~F}$ & No & Normal & Normal & Normal & Normal \\
\hline $11-3$ & $58 \mathrm{M}$ & No & Minor Q waves & $\begin{array}{l}\text { Septal bulge in LVOT: } \\
14 \mathrm{~mm}, \mathrm{MR} \text { grade I }\end{array}$ & FHC-major & Ala295Ser \\
\hline II-4 & $56 \mathrm{~F}$ & $\begin{array}{l}\text { Angina, dyspnea } \\
\text { syncopes }\end{array}$ & LBBB & $\begin{array}{l}\text { Previous obstructive } \\
\text { FHC, septum presently: } \\
13 \mathrm{~mm} \text {, AR grade II }\end{array}$ & FHC-major & Ala295Ser \\
\hline III-1 & $37 \mathrm{~F}$ & No & $\begin{array}{c}\text { Free left } \\
\text { posteroseptal WPW }\end{array}$ & $\begin{array}{c}\text { FHC, posterior septum: } \\
19 \mathrm{~mm}\end{array}$ & FHC-major & Ala295Ser \\
\hline III-2 & $34 \mathrm{~F}$ & No & Minor Q waves & $\begin{array}{l}\text { Septal bulge in LVOT: } \\
14 \mathrm{~mm}\end{array}$ & FHC-major & Ala295Ser \\
\hline III-3 & $28 \mathrm{M}$ & No & Normal & Normal & Normal & Ala295Ser \\
\hline II-6 & $54 \mathrm{M}$ & No & Minor Q waves & $\begin{array}{l}\text { Septal bulge in LVOT: } \\
14 \mathrm{~mm} \text {, AR grade I }\end{array}$ & FHC-major & Ala295Ser \\
\hline III-4 & $29 M$ & No & $\begin{array}{l}\text { Minor Q waves and } \\
\text { ST-segment changes }\end{array}$ & Normal & FHC-minor & Ala295Ser \\
\hline III-5 & $25 \mathrm{~F}$ & No & Major Q waves & Normal & FHC-major & Ala295Ser \\
\hline $11-8$ & $52 \mathrm{~F}$ & No & Normal & $\begin{array}{l}\text { MVP, MR grade I, free } \\
\text { anterior wall: } 13 \mathrm{~mm}\end{array}$ & FHC-minor & Ala295Ser \\
\hline $11-9$ & $51 \mathrm{M}$ & No & $\begin{array}{l}\text { Borderline left ventricular } \\
\text { hypertrophy }\end{array}$ & MR grade I & $\begin{array}{l}\text { Excluded, known } \\
\text { hypertension }\end{array}$ & Normal \\
\hline II-10 & $48 \mathrm{~F}$ & No & $\begin{array}{l}\text { Minor Q waves, borderline } \\
\text { left ventricular hypertrophy }\end{array}$ & $\begin{array}{l}\text { Septal bulge in } \\
\text { LVOT:14 mm, } \\
\text { MR grade I }\end{array}$ & FHC-major & Ala295Ser \\
\hline III-6 & $26 \mathrm{M}$ & No & Minor Q waves & $\begin{array}{l}\text { Septal bulge in LVOT: } \\
15 \mathrm{~mm}\end{array}$ & FHC-major & Ala295Ser \\
\hline III-7 & $25 \mathrm{M}$ & No & Left ventricular hypertrophy & MVP & FHC-major & Ala295Ser \\
\hline III-8 & $21 \mathrm{~F}$ & No & Minor Q waves & Normal & FHC-minor & Ala295Ser \\
\hline
\end{tabular}

${ }^{A}$ Clinical data on individuals I-2 and I-3 were obtained from hospital records. Echocardiogram done on individual I-2 only. ${ }^{\mathrm{B} M u t a t i o n}$ analysis of individual I-2 was not possible, as the amount of PCR product was only sufficient for establishing the haplotype (Figure 1a). * Deceased. AR, aortic regurgitation. IHD, ischemic heart disease. LBBB, left bundle branch block. LVOT, left ventricle outflow tract. MR, mitral regurgitation. MVP, mitral valve prolapse. SAM, systolic anterior motion of the mitral valve. 
they involve force transmission from the sarcomere to the surrounding syncytium. This hypothesis is supported by analyses of an ACTC knockout mouse transgenetically modified to express $\gamma$ enteric actin instead of $\alpha$-cardiac actin in the heart muscle (30). The 2 actins differ by 5 amino acids at positions of putative binding sites to myosin and anchor polypeptides $(27,28)$. The hearts of these mice shared the features of FHC: they had diastolic dysfunction and were hypertrophied, with the same histological features seen in humans. In addition, the hearts had features of IDC: they were enlarged and had impaired systolic function. Based on similarities between the findings in humans, in whom mutations in different functional domains of $\alpha$-cardiac actin may lead to either FHC or IDC, and the findings in the mouse model, having features of both diseases, the suggested pathophysiological mechanism appears to be very likely.

\section{Acknowledgments}

We thank K.E. Sørensen and J.J. Hansen for useful discussions, and U. Steffensen for excellent technical assistance. This work was supported by The Faculty of Health Sciences (University of Aarhus), The Danish Heart Foundation, The Danish Medical Research Council, The Novo Nordic Foundation, and The Institute of Experimental Clinical Research (University of Aarhus).

1. Maron, B.J. 1997. Hypertrophic cardiomyopathy. Lancet. 350:127-133.

2. Bonne, G., Carrier, L., Richard, P., Hainque, B., and Schwartz, K. 1998. Familial hypertrophic cardiomyopathy: from mutations to functional defects. Circ. Res. 83:580-593.

3. Marian, A.J., and Roberts, R. 1998. Familial hypertrophic cardiomyopathy: a paradigm of the cardiac hypertrophic response to injury. Ann. Med. 30(Suppl. 1):24-32.

4. Towbin, J.A. 1998. The role of cytoskeletal pro- teins in cardiomyopathies. Curr. Opin. Cell Biol. 10:131-139.

5. MacRae, C.A., et al. 1995. Familial hypertrophic cardiomyopathy with Wolff-Parkinson-White syndrome maps to a locus on chromosome $7 \mathrm{q} 3$. J. Clin. Invest. 96:1216-1220.

6. Flavigny, J., et al. 1998. Identification of two novel mutations in the ventricular regulatory myosin light chain gene (MYL2) associated with familial and classical forms of hypertrophic cardiomyopathy. J. Mol. Med. 76:208-214.

7. Kimura, A. 1997. Symposium on gene abnormalities in medical diseases. III. Molecular genetics of hypertrophic cardiomyopathy in Japan. Intern. Med. 36:152-154.

8. Charron, P., et al. 1997. Diagnostic value of electrocardiography and echocardiography for familial hypertrophic cardiomyopathy in a genotyped adult population. Circulation. 96:214-219.

9. Lathrop, G.M., Lalouel, J.M., Julier, C., and Ott, J. 1984. Strategies for multilocus linkage analysis in humans. Proc. Natl. Acad. Sci. USA. 81:3443-3446.

10. Niimura, H., et al. 1998. Mutations in the gene for cardiac myosin-binding protein $\mathrm{C}$ and lateonset familial hypertrophic cardiomyopathy. $N$. Engl. J. Med. 338:1248-1257.

11. Mogensen, J., Kruse, T.A., and Børglum, A.D. Assignment of the human skeletal muscle $\alpha$-actin gene (ACTA1) to chromosome $1 \mathrm{q} 42.13$ $\mathrm{q} 42.2$ by radiation hybrid mapping. Cytogenet. Cell Genet. In press.

12. The Stanford Human Genome Center. www.shgc.stanford.edu. Accessed April 18, 1998.

13. The Wellcome Trust Center for Human Genetics. www.well.ox.ac.uk. Accessed April 18, 1998.

14. Schwartz, K., et al. 1992. Exclusion of cardiac myosin heavy chain and actin gene involvement in hypertrophic cardiomyopathy of several French families. Circ. Res. 71:3-8.

15. Mogensen, J., Kruse, T.A., and Børglum, A.D. Refined localization of the human $\alpha$-tropomyosin gene (TPM1) by genetic mapping. Cytogenet. Cell Genet. In press.

16. Litt, M., and Luty, J.A. 1989. A hypervariable microsatellite revealed by in vitro amplification of a dinucleotide repeat within the cardiac muscle actin gene. Am. J. Hum. Genet. 44:397-401.

17. Mogensen, J., Kruse, T.A., and Borglum, A.D. 1997. Assignment of the human cardiac troponin I gene (TNNI3) to chromosome $19 \mathrm{q} 13.4$ by radiation hybrid mapping. Cytogenet. Cell Genet. 79:272-273.

18. The Whitehead Institute. www.genome.wi.mit.edu. Accessed April 18, 1998.

19. Dib, C., et al. 1996. A comprehensive genetic map of the human genome based on 5,264 microsatellites. Nature. 380:152-154.

20. Sandvej, K., Peh, S.C., Andresen, B.S., and Palle- sen, G. 1994. Identification of potential hot spots in the carboxy-terminal part of the Epstein-Barr virus (EBV) BNLF-1 gene in both malignant and benign EBV-associated diseases: high frequency of a 30-bp deletion in Malaysian and Danish peripheral T-cell lymphomas. Blood. 84:4053-4060.

21. Hamada, H., Petrino, M.G., and Kakunaga, T. 1982. Molecular structure and evolutionary origin of human cardiac muscle actin gene. Proc. Natl. Acad. Sci. USA. 79:5901-5905.

22. Baumgartner, H., Kratzer, H., Helmreich, G., and Kuhn, P. 1988. Quantitation of aortic regurgitation by colour coded cross-sectional Doppler echocardiography. Eur. Heart J. 9:380-387.

23. Boheler, K.R., et al. 1991. Skeletal actin mRNA increases in the human heart during ontogenic development and is the major isoform of control and failing adult hearts. J. Clin. Invest. 88:323-330.

24. Olson, T.M., Michels, V.V., Thibodeau, S.N., Tai, Y.S., and Keating, M.T. 1998. Actin mutations in dilated cardiomyopathy, a heritable form of heart failure. Science. 280:750-752.

25. Protein alignment database. www-nbrf.georgetown.edu/cgi-bbin/nbrfget?uid=FA0722\&db=8 Accessed December 10, 1998

26. Gregorio, C.C. 1997. Models of thin filament assembly in cardiac and skeletal muscle. Cell Struct. Funct. 22:191-195.

27. Levine, B.A., Moir, A.J., Patchell, V.B., and Perry, S.V. 1992. Binding sites involved in the interaction of actin with the $\mathrm{N}$-terminal region of dystrophin. FEBS Lett. 298:44-48.

28. Rayment, I., et al. 1993. Structure of the actinmyosin complex and its implications for muscle contraction. Science. 261:58-65.

29. Zot, A.S., and Potter, J.D. 1987. Structural aspects of troponin-tropomyosin regulation of skeletal muscle contraction. Annu. Rev. Biophys. Biophys. Chem. 16:535-559.

30. Kumar, A., et al. 1997. Rescue of cardiac alphaactin-deficient mice by enteric smooth muscle gamma-actin. Proc. Natl. Acad. Sci. USA. 94:4406-4411.

31. Vikstrom, K.L., Factor, S.M., and Leinwand, L.A 1996. Mice expressing mutant myosin heavy chains are a model for familial hypertrophic cardiomyopathy. Mol. Med. 2:556-567.

32. Baandrup, U. and Olsen, E.G. 1981. Critical analysis of endomyocardial biopsies from patients suspected of having cardiomyopathy. I. Morphological and morphometric aspects. $\mathrm{Br}$. Heart J. 45:475-486.

33. Kabsch, W., Mannherz, H.G., Suck, D., Pai, E.F., and Holmes, K.C. 1990. Atomic structure of the actin:DNase I complex. Nature. 347:37-44.

34. Protein database. www.pdb.bnl.gov, entry: 1 ATN Accessed December 10, 1998. 